\title{
\#EdTechHub
}

\section{Bangladesh Back-to-School Campaign}

Tom Kaye, Rachel Chuang, Caitlin Moss Coflan, Björn Haßler

May 2020

For enquiries please email helpdesk@edtechhub.org. 


\section{About this document}

Recommended Tom Kaye, Rachel Chuang, Caitlin Moss Coflan, Björn Haßler (2020). citation. Bangladesh Back to School Campaign. (EdTech Hub Helpdesk Response No 18). Available under Creative Commons Attribution 4.0 International, https://creativecommons.org/licenses/by/4.0/.

Licence. Creative Commons Attribution 4.0 International

https://creativecommons.org/licenses/by/4.0/.

You - dear readers - are free to share (copy and redistribute the material in any medium or format) and adapt (remix, transform, and build upon the material) for any purpose, even commercially. You must give appropriate credit, provide a link to the license, and indicate if changes were made. You may do so in any reasonable manner, but not in any way that suggests the licensor endorses you or your use.

Identifiers. $\quad$ 2405685:3HP24UTI; DOI: 10.5281/zenodo.3865298

Internal use. g/d/1EGiVwmgggc2GR3aupGgpt2EOG fT8WCxFdgYJ9ANYmI

Version 1

2020-05-29 
2. Bangladesh context 6

2.1. Education system and progress $\quad 6$

Figure 1. Students and teachers by gender in Bangladeshi public education (Source: Bangladesh Bureau of Educational Information and Statistics).

$\begin{array}{ll}\text { 2.2. Learning continuity plan } & 7\end{array}$

Radio $\quad 7$

$\begin{array}{ll}\text { Television } & 7\end{array}$

$\begin{array}{ll}\text { Mobile phones } & 7\end{array}$

Internet 8

2.3. Analysis of learning continuity plan 8

Better identify student segments 8

Figure 2. Radar chart on technology. $\quad 9$

Figure 3. Radar chart on technologies completed for different population segments.

$\begin{array}{ll}\text { Better target marginalised learners } & 10\end{array}$

3. Return to school campaigns following disruptions 11

Radio 11

$\begin{array}{ll}\text { Television } & 11\end{array}$

$\begin{array}{ll}\text { Mobile phones } & 11\end{array}$

$\begin{array}{ll}\text { Internet } & 12\end{array}$

4. Focus areas and recommendations 13

4.1. Start planning early and align actors 13

Figure 4. Actors involved in school reopenings and promoting safe schools (Theirworld, 2018). 13

Box 1. Recommendation for Bangladesh: Build partnerships. 14

4.2. Establish regular communications with the local community 14

Box 2. Recommendation for Bangladesh: Leverage existing ICT platforms and resources. $\quad 15$

4.3. Work with schools to set up sanitation and safety procedures 15

Box 3. Recommendation for Bangladesh: Take action to ensure hygiene and social distancing. 15

4.4. Support students physically, mentally and financially 16

Box 4. Recommendation for Bangladesh: Leverage cross-sectoral opportunities. 
4.5. Focus on marginalised learners

Box 5. Recommendation for Bangladesh: Ensure marginalised learners are supported.

4.6. Equip teachers with support and curriculum materials

Box 6. Recommendation for Bangladesh: Share Open Educational Resources (OER) with teachers for professional development and lesson planning.

4.7. COVID-19 accelerated funding and back-to-school strategies

Figure 5. Mapping key elements of back to school strategies to GPE funding proposals (Global Partnership for Education, 2020b). Sources: COVID-19 Accelerated Funding Applications from Ghana, Malawi, Mozambique, Rwanda, and Zambia.

References

Annex: Back to school activities outlined in GPE funding proposals 


\section{Introduction}

The COVID-19 pandemic has resulted in the largest disruption to schooling since the second world war. At the peak of its impact on education systems, schools were closed in nearly 200 countries with almost 1.5 billion learners affected (UNESCO, 2020).

Countries have moved quickly to respond to this crisis. Technologies including print, radio, television, phones and online have been leveraged to support learning. This has helped to ensure some continuity of education during the pandemic.

While distance education may help limit COVID-19's negative impact on learners, it is no substitute for school-based education. Recent modelling from the US indicated that three months of school closures may result in learners losing a whole year of learning gains (Tarasawa, 2020). The ramifications in countries where distance learning systems are less robust may be significantly worse.

School closures in low- and middle-income countries are expected to have long-term negative impacts, including increased inequality and decreased health outcomes (UNESCO, UNICEF, World Bank \& WFP, 2020). The impact of school closures will be particularly damaging for marginalised students, who are already less likely to be in school. These groups face additional risk factors from being out of school, including violence, sexual abuse, being integrated into child labour schemes, and stress and anxiety. Ensuring learners return to school will play a critical role in determining how countries rebound from the COVID-19 crisis. Ensuring children rapidly return to school as soon as it is safe and practical is a crucial next step in supporting children's learning and life outcomes in these contexts.

The UK Department for International Development (DFID) is investigating providing support to Bangladesh's Ministry of Primary and Mass Education (MoPME) and Directorate of Primary Education (DPE) to develop a back-to-school campaign. The EdTech Hub received a request from the DFID Bangladesh team to provide a topic brief identifying best practices from previous back-to-school campaigns following disruptions. 


\section{Bangladesh context}

This section describes the context for this request, in particular, the education system, and the learning continuity plan. It also presents an analysis of the learning continuity plan.

\subsection{Education system and progress}

Bangladesh has one of the largest public education systems in the world, with more than 30 million students participating in primary and secondary education. These students are taught by nearly one million teachers.

Figure 1. Students and teachers by gender in Bangladeshi public education (Source: Bangladesh Bureau of Educational Information and Statistics).

\begin{tabular}{|l|c|c|c|}
\hline \multicolumn{4}{|c|}{ Students } \\
\hline \multicolumn{1}{|c|}{ Level } & Total & Girls & Boys \\
\hline Primary & $17,338,100$ & $8,799,033$ & $8,539,067$ \\
\hline Secondary & $12,885,346$ & $6,951,936$ & $5,933,410$ \\
\hline TOTAL & $30,223,446$ & $15,750,969$ & $14,472,477$ \\
\hline & \multicolumn{2}{|c|}{ Teachers } & \\
\hline Level & Total & Male & Female \\
\hline Primary & 685,400 & 258,749 & 426,651 \\
\hline Secondary & 234,165 & 174,095 & 60,070 \\
\hline TOTAL & 919,565 & 432,844 & 486,721 \\
\hline
\end{tabular}

Over the last ten years, Bangladesh has made substantial progress in increasing school access. As of 2018, primary net enrolment stood at $97.9 \%$ (98.3\% for girls), up from $90.8 \%$ in 2008 . Secondary net enrolment was at $69.4 \%$ (74.4\% for girls), up from $61.4 \%$ in 2008. Over the same period, cycle completion rates have increased for both primary (from $50.7 \%$ to $71.4 \%$ ) and secondary (from $38.62 \%$ to $63.28 \%$ ).

With access steadily increasing, education leaders are now focused on improving quality. The number of teachers is increasing, and student-teacher ratios have begun to fall (i.e., from 47-1 in 2010 to 38-1 in 2018). Work to reform the curriculum and assessment approaches is ongoing. Teachers are receiving more and better professional development opportunities, and the quality of textbooks and teaching and learning materials continues to improve.

With the foundations to improve learning in place, COVID-19 poses a significant risk to Bangladesh's education system. It is imperative the momentum built over the last ten 
years of reform is not lost due to disruptions. With schools closed since March 17, 2020 and recent reports anticipating that closures may continue until September, Bangladesh must act quickly to ensure these gains are not lost (Uttom \& Rozario, 2020).

\subsection{Learning continuity plan}

Bangladesh has already taken steps to provide learners with educational continuity. A learning continuity plan, focused on distance learning opportunities, has been created (Ministry of Primary and Mass Education, 2020). The plan identifies interventions that are either already underway or are planned for execution in coming weeks. The plan uses a multimodal approach that leverages radio, television, mobile phones and the internet.

\section{Radio}

Public service announcements are deployed on both national and community radio. Announcements last for a total of 32 minutes per day at a cost of GBP 400 per day. These focus on providing updates on the schooling situation, providing guidance on priority subjects and topics of the day, and inspiring students. One hour of academic coaching and one hour of live teaching are broadcast for primary and secondary every day. The cost of these activities is approximately GBP 2,500 per day. Although the cost of leveraging this mechanism is low, only approximately $0.6 \%$ of Bangladeshi households have access to radios. However, in the case of Bangladesh, $0.6 \%$ of primary and secondary learners is 1.8 million students. If all students with radios access this service, this equates to a cost of 1.5 GBP to reach approximately 1,000 learners per day. All audio content broadcast on radio is being uploaded to the online platform referenced below.

\section{Television}

Bangladesh's Parliament TV channel is being used to broadcast lessons for pre-primary, primary, secondary, technical and madrasah education. A total of 1,440 20-minute classes are being screened to the end of June at a total cost of GBP 525,000 (or GBP 365 per lesson). Other TV-based initiatives include teacher development (12 one-hour sessions), live sessions for students (6 thirty-minute sessions) and live sessions for parents (12 thirty-minute sessions). While formal data does not exist, anecdotal information provided by UNICEF estimates that $60 \%-80 \%$ of students (or approximately 24 million learners) are watching classes on TV. While the cost of television-based learning is higher than radio, its extended reach provides a better return on investment. All video content broadcast on TV is being uploaded to the online platform referenced below.

\section{Mobile phones}

Mobile phones are being deployed in various ways to support learning and engagement. A bulk-messaging platform is leveraged to disseminate class schedules, provide interactive quizzes, provide teachers with notifications and collect opinions and feedback. While a pilot for a telephone hotline with 10,000 teachers was previously underway, it is now on hold. Instead, the National Call Centre will be opened, with the 
support of the ICT Ministry, to connect over 450,000 teachers with students. Students can call 3336 to ask questions to a teacher from a specific grade and subject. Teachers become eligible to provide support through this platform by completing an online training course. The calls will be considered part of a teacher's regular activities and salaried work. There is ongoing discussion with mobile operators for high-performing teachers to receive a data package.

While teachers receive no additional income for receiving calls in the short term, there is a long-term plan to use the platform to provide student tutoring. It is envisaged that this will provide a formalised alternative to the informal, paid, out-of-school tutoring provided by teachers to Bangladeshi students. Given that a shortage of teachers has been identified in Bangladesh (e.g., 749 schools report only one teacher; 1,124 schools report only two teachers), the hotline could serve as both a short- and long-term initiative (Directorate of Primary Education, 2019).

\section{Internet}

Bangladesh has made a significant investment in increasing its internet-based distance education offerings. An Edu-Hub portal has been created in partnership with over 27 organisations and is being populated with content (EduHub Bangladesh, 2020). Students can view video recordings and take interactive quizzes through the platform.

\subsection{Analysis of learning continuity plan}

Bangladesh's efforts to develop and implement the learning continuity plan have moved rapidly, demonstrating both innovation and the ability to leverage existing assets to ensure value for money. Other considerations that could help further enhance the existing initiatives outlined in the learning continuity plan are listed below.

\section{Better identify student segments}

Student segments should be identified prior to implementing an effective, multi-modal strategy. Determining where students share common circumstances and settings can help determine the best modalities to reach all students. Segmenting might be done by categories including:

- location (e.g., urban, regional, rural, remote),

- socio-economic status (low- through to high-income),

- access to modalities (internet, phone, etc.),

- age groups (primary, secondary),

- special educational needs or disabilities, as well as

- belonging to specific marginalised groups (e.g., by gender).

Once segments have been identified, the diagramme in Figure 2 can be used as a tool to map the availability of different modalities. This can help identify ways to meet the needs of each segment. Figure 3 shows how the tool might look when completed, identifying how different segments might be mapped on the tool. 
Figure 2. Radar chart on technology.

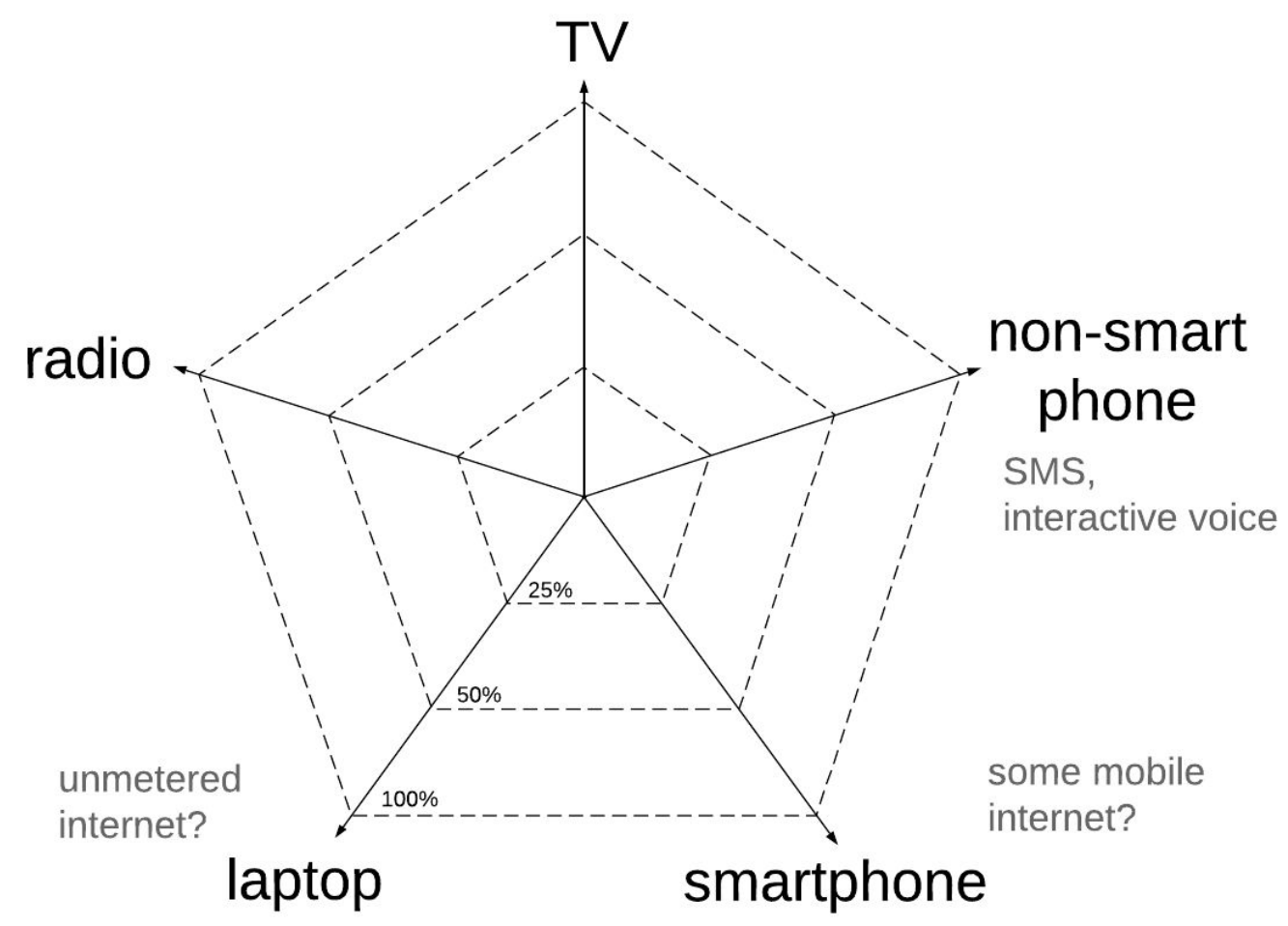

Figure 3. Radar chart on technologies completed for different population segments.

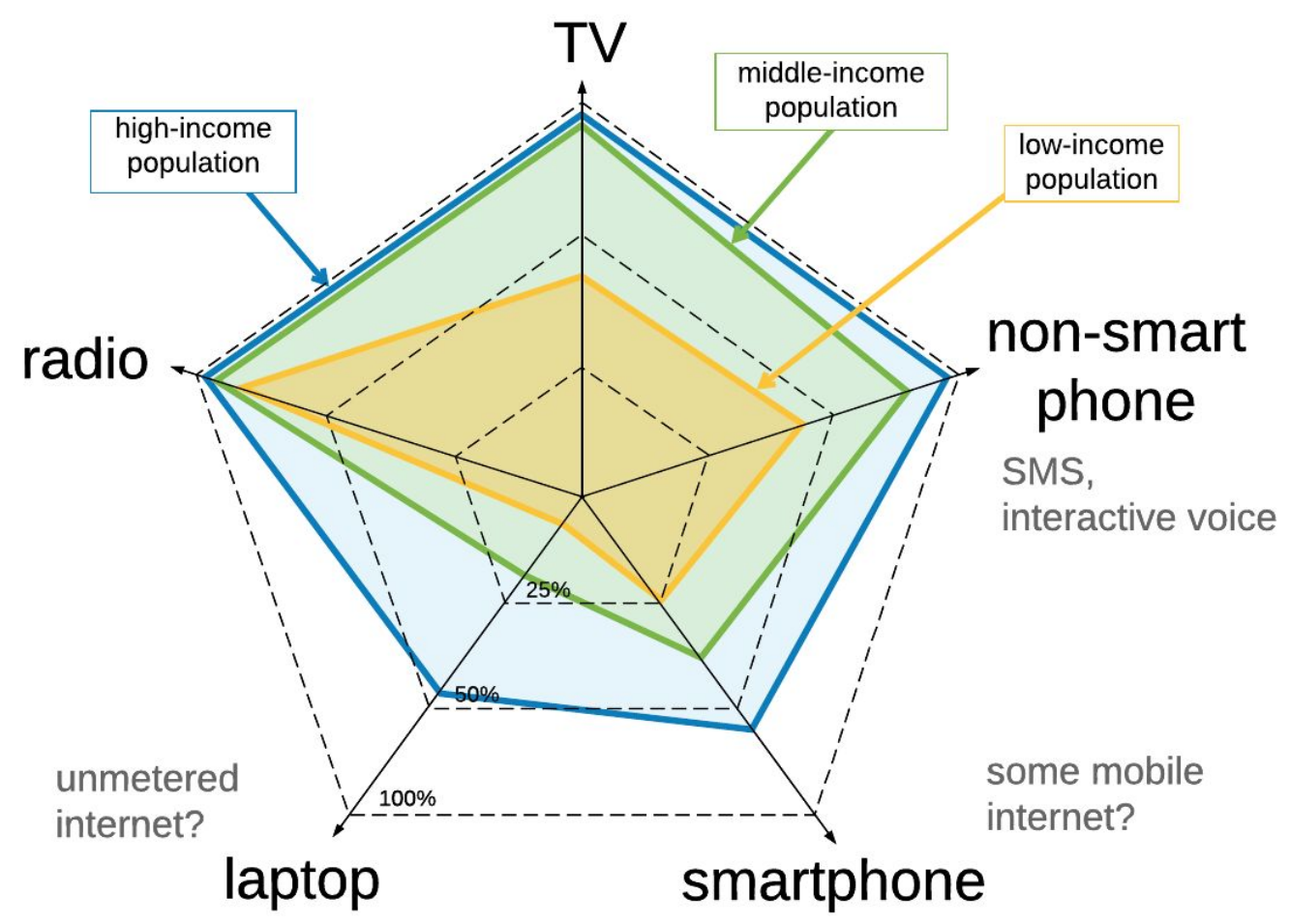

While Bangladesh has made some efforts to target student segments, there has been a large focus of investment on students in urban centres. More active targeting of 
marginalised and hard-to-reach students is required. For example, a large investment has been allocated to enhance Bangladesh's online EduHub portal. While EduHub serves as a one-stop shop for educational resources, it only reaches children who have internet access, primarily in urban regions. Children in remote areas and without the socio-economic means to access the internet will not benefit from these investments.

However, it is important to note that government and development partners have worked collaboratively to address needs as they have been identified. For example, early in the implementation of the learning continuity plan, feedback indicated that the majority of the 2.7 million children receiving non-formal education did not have access to the internet. The UNICEF Bangladesh team identified mobile phones as an effective modality to support these learners. A series of 10-15-minute lessons over a conference call are currently being held with children outside the formal education system.

Alternative learning pathways and non-formal education programmes will require additional focus for a back to school strategy.

\section{Better target marginalised learners}

While Bangladesh has made great progress in providing a wide range of distance learning resources to a majority of learners, work needs to be done to ensure the most marginalised learners are not left behind. For example, children in hard-to-reach areas without internet access, radio or TV have little access to learning opportunities. Similarly, learners with special needs could be better targeted through distance learning. For example, TV courses as part of the learning continuity plan do not presently incorporate sign language. When developing a back to school campaign, additional supports for SEND students should be included. 


\section{Return to school campaigns following disruptions}

While the disruption caused by COVID-19 is significant, there have been other disruptions to schooling in a wide range of countries over past decades. Some disruptions have been regional (e.g., those caused by Ebola between 2013 and 2016 and the Asian financial crisis between 1997 and 1999). Other disruptions have been country specific (e.g., civil wars, natural disasters, etc.). In Bangladesh, disruptions to schooling often stem from political protests/strikes (hartals) or natural disasters (Bhattacherjee, 2018). Though hartals typically last only for a few days or weeks, they also create disruptions in student learning, which have provided valuable lessons.

This section analyses return-to-school campaigns from the past years to identify trends that could be used to inform Bangladesh's back-to-school campaign. The section further examines how the modalities Bangladesh is using to deliver distance education have been leveraged to support campaigns in other contexts.

\section{Radio}

In 2015, during the Ebola epidemic, solar radios were distributed to communities in Guinea by UNICEF. In parallel, radio stations broadcasted messages about safety protocols and how to prevent Ebola. Once schools reopened, the Ministry of Education broadcasted messages about the start of the school year through 28 radio stations (Interagency Collaboration on Ebola, 2015).

Ghana recently received funding from the Global Partnership for Education (GPE) to support its COVID-19 response. The proposal highlighted a back-to-school strategy that utilised radio and TV to publicise health, safety and the importance of returning to school. The campaign will be launched across 16 regions within 60 days of schools reopening (Global Partnership for Education, 2020a).

\section{Television}

In 2015, the International Organization for Migration (IOM) and the National Guinean Theater Association produced a television mini-series in response to Ebola. The mini-series was used as a discussion tool in local communities in Guinea to educate people about Ebola and reduce stigma against survivors (Interagency Collaboration on Ebola, 2015). In Liberia, UNICEF delivered messaging about Ebola through community cinema nights for individuals that did not have a television at home (Inveneo, 2014).

\section{Mobile phones}

DFID and the Sierra Leone Ministry of Education partnered with local communities to collect monthly updates from schools. From these updates, they identified where there was support to reopen after the Ebola epidemic. SMS messaging was a cheap and easily scalable option for both one-way and two-way communication between actors. Phones were used to send messages both to raise awareness and to identify concerns from the community. Information shared via SMS was integrated into the government's data collection system (Berry, 2015; Davis \& Berry, 2020). 


\section{Internet}

In 2017, Lebanon's Ministry of Education and Higher Education deployed a back-to-school campaign focused on 'school heroes.' The community celebrated students, teachers, parents, bus drivers, and others committed to education (UNICEF, 2017). The campaign highlighted the role of each community member in enabling access to education for all children. Videos on school heroes were shared on social media platforms with the support of local influencers. A telephone hotline was also set up to respond to school enrollment questions from parents and caregivers (UNICEF, 2017). 


\section{Focus areas and recommendations}

Safety concerns, financial burdens, and limited support for marginalised learners may lead to a slow return to previous rates of enrollment even after schools are reopened (Tounsi, 2018; Giannini, Jenkins \& Saavedra, 2020). Back-to-school campaigns must address each of these demand-side barriers to education. Supply-side constraints such as teacher attendance, school readiness to resume functions, and the ability of the school to ensure student safety should also be addressed.

This section highlights six key areas programme designers and policy-makers consider when implementing return-to-school campaigns. Each area highlights considerations / recommendations for Bangladesh. Finally, the section looks briefly at other back-to-school campaigns that have received funding through the GPE COVID-19 accelerated funding round.

\subsection{Start planning early and align actors}

Planning for school reopenings should begin as soon as possible (Giannini, Jenkins \& Saavedra, 2020). A detailed plan outlining communication channels, content and timelines should be created in partnership with all relevant Ministries (e.g., Education, Health, Finance, etc.). Other actors that may be involved include national governments, international organisations, NGOs, CSOs, business, and academia (see Figure 4) (Theirworld, 2018).

Figure 4. Actors involved in school reopenings and promoting safe schools (Theirworld, 2018).

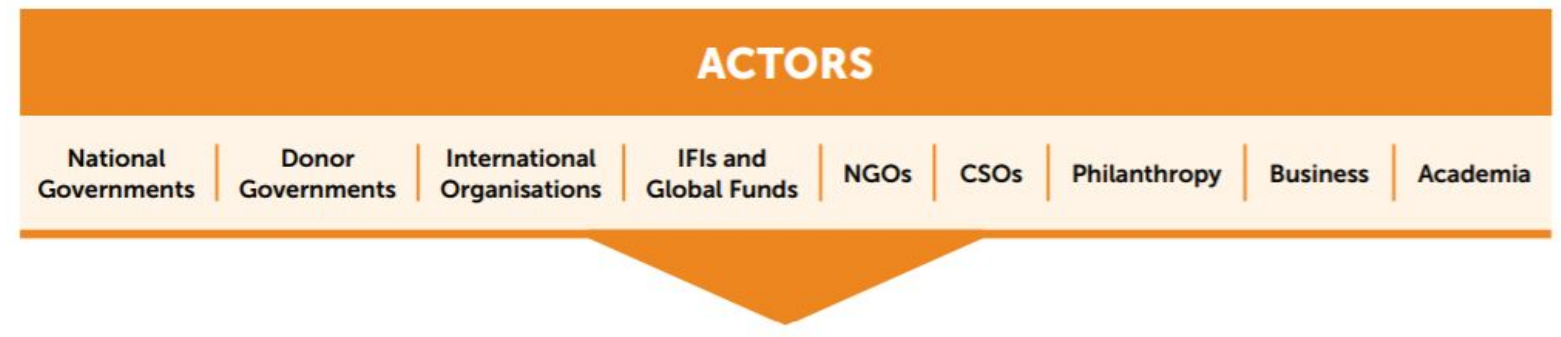

Widespread alignment and transparency is necessary to ensure a unified response to school disruptions. Coordination among actors allows for buy-in and collective decision-making on back-to-school initiatives and timing. It can prevent mixed messaging to learners, parents and families about returning to school. High involvement from community support groups and school committees can positively impact the return-to-school process. These groups can support data collection and facilitate interaction with parents who may be hesitant to send their children to school (UNICEF, 2013). For example, youth community groups in Sierra Leone played an important role in monitoring Ebola cases and improving educational responses (Berry, 2015). Raising awareness about the plan can also help build confidence in school reopenings. 
For governments weighing decisions on school reopening, one useful tool is a framework developed by UNESCO, UNICEF, World Bank and WFP. The framework covers three major areas:

1. why reopen schools,

2. when, where and which schools to reopen, and

3. how to reopen schools.

Prior to reopening, governments must weigh the risks associated with school reopenings against the value of returning to classroom-based lessons.

\section{Box 1. Recommendation for Bangladesh: Build partnerships.}

Strong partnerships between key actors are required to allow Bangladesh to effectively reopen schools. Collaboration is already taking place through the platform EduHub Bangladesh, recently launched by the government, A2I and other NGOs (EduHub Bangladesh, 2020). A back-to-school campaign developed by $A 21$ is in progress, though there is limited information currently available. Collaboration between DFID and A2I to support a back-to-school strategy could build upon the existing education continuity plan. As A2I already provides technical support for class recordings and broadcasts, further partnership would be both valuable and feasible.

\subsection{Establish regular communications with the local community}

Open communication with families, teachers, students, local authorities and communities is required to ensure that all stakeholders feel informed about and comfortable with the return-to-school process. For example, if parents are concerned about their children's health and safety it is unlikely that they will send their children to school. Understanding and addressing barriers to school attendance and feedback from parents and caregivers is necessary (Giannini, Jenkins \& Saavedra, 2020).

During 2018, in the Democratic Republic of Congo (DRC), parents were wary of sending their children to school where they could contract Ebola. In response, UNICEF established an information campaign to equip school principals and teachers to answer questions and hesitations from parents. Educators learned about the virus, prevention tactics, and how to raise awareness in the community while limiting panic (Daems \& Willemot, 2018).

Activities that might be used to communicate back-to-school messaging can also include:

- home visits by teachers (while maintaining social distancing),

- local community parades,

- sports, music, poetry, art and drama competitions, and

- shows by local performance groups (UNICEF, 2013).

In 2002, UNICEF encouraged children and teachers in Afghanistan to return to school through a national campaign. The strategy included radio messages, street drama, community meetings, and thousands of posters, stickers, and banners (UNICEF, 2013). 
Box 2. Recommendation for Bangladesh: Leverage existing ICT platforms and resources.

Where possible, the government should leverage existing ICT infrastructure, such as from the distance-learning strategy. Short public service announcements (PSAs) can be recorded and broadcast on radio, Sangshad TV, and other channels. As per the COVID-19 Response Education Continuity Plan, there is no airing cost for Sangshad TV. Cost negotiations will need to be held with radio and other TV networks.

SMS messaging platforms can be repurposed from the learning continuity plan to inform stakeholders about the return to school. Bulk messages can be sent to student phone numbers that are already compiled through the student stipend database. Parents and families can reach out with questions about school reopenings and enrollment through the National Call Centre.

\subsection{Work with schools to set up sanitation and safety procedures}

Schools must be sufficiently cleaned and disinfected prior to reopening, to both protect students and to address parents' concerns. In Sierra Leone, over 36,000 hand-washing stations were distributed prior to the reopening of schools. Similarly, in Guinea, new sanitation infrastructure and latrines were upgraded in 850 schools (World Bank, 2015). In Liberia, students had to wash their hands in chlorinating water and have their temperatures measured prior to entering the classroom (Watt, 2020).

Box 3. Recommendation for Bangladesh: Take action to ensure hygiene and social distancing.

In Bangladesh, $76 \%$ of schools have WASH blocks and $85 \%$ have a safe water supply (Directorate of Primary Education, 2019). However, WASH blocks do not always contain hand-washing stations with running water and soap (Ministry of Primary and Mass Education, 2020). Sanitation facilities, safe water and public health supplies (e.g., chlorine, rubber gloves, buckets) can be provided across schools (Global Business Coalition for Education, 2014). Beyond hygiene and sanitation, it is necessary to ensure appropriate social distancing even after schools reopen. Based on the 2019 Bangladesh Primary Education Annual Sector Performance Report, a 26' x 19'6" classroom is of sufficient size for 40 students. About $54 \%$ of schools in Bangladesh met this standard in 2018 (Directorate of Primary Education, 2019).

Reorganisation of the school day, such as double-shifting and blended learning approaches, is recommended (International Institute for Educational Planning, 2020). Double-shifting will reduce overcrowding and may prevent transmission of COVID-19. Alternatively, blended learning could be used to combine in-person instruction with remote coursework. Students can attend school for part of the day and complete coursework at home through the use of various modalities. 


\subsection{Support students physically, mentally and financially}

In the midst of the COVID-19 pandemic, students and families may experience multiple types of burdens and stressors. The back-to-school strategy should address the physical, mental and financial needs of students recovering from the aftermath of the pandemic.

Within the community, schools can provide essential services, including food. The United Nations WFP is already working in Bangladesh to distribute high-energy biscuits to over three million children who are out of school (WFP, 2020). Establishing a feeding programme will counter malnutrition and serve as a financial incentive to send children back to school (Global Business Coalition for Education, 2014). School feeding programmes can establish a sense of routine for the families while allowing parents time to grieve, recover and find employment (Briggs, 2018).

Supporting the socio-emotional wellbeing of students and teachers is important (Giannini, Jenkins \& Saavedra, 2020). Where possible, non-essential tests / exams should be waived to reduce stress for students (UNESCO, UNICEF, World Bank, \& WFP, 2020). For students who have experienced trauma or life events as a result of COVID-19, governments should provide psychosocial and child protection services (Global Business Coalition for Education, 2014). For example, in 2015, various organisations provided mental health and other support services to Liberians affected by Ebola. ACF incorporated psychosocial support within their existing programmes to reach 14,000 Liberians. Plan International, in partnership with the Ministry of Gender and Social Protection and UNICEF, conducted sessions on trauma healing for families. CARE International connected survivor support groups with the Village Savings and Loans Associations (VSLAs) network for livelihood assistance (Interagency Collaboration on Ebola, 2015).

Parents may not be able to afford tuition fees after the outbreak due to loss of jobs or time spent in quarantine (Watt, 2020). Governments should make adjustments accordingly to encourage student attendance. In response to the Ebola epidemic, the government of Sierra Leone waived examination fees and subsidised secondary school fees for two years (World Bank, 2015). Other incentives encompass providing school uniforms and offering scholarships for children who are most at risk of not returning to school (UNICEF, 2013).

\section{Box 4. Recommendation for Bangladesh: Leverage cross-sectoral opportunities.}

Existing student support programmes will become integral to a back-to-school strategy once schools reopen. Programmes include the Primary Education Stipend Project (PESP) and the School Feeding Programme (SFP), which support over 14 million children collectively. Further consideration is required on how to scale these programmes, given that the need for support across Bangladeshi students will increase due to the COVID-19 pandemic (Directorate of Primary Education, 2019).

A back-to-school campaign should last more than a few weeks, given that some students may not return right away. Students taking on jobs to support their families 
can require further incentives (e.g., cash transfers) or may need to access school via flexible modalities or time requirements.

\subsection{Focus on marginalised learners}

The most vulnerable and marginalised groups (e.g., girls, children with disabilities, ethnic and religious minorities) should be prioritised in a back-to-school strategy. These students are often disproportionately affected by having to move to remote learning, as remote learning has generally been found to be more successful among students from higher socio-economic segments. Schools should provide targeted support to these learners to ensure they return to school, including identifying and removing barriers to school entry. Initiatives can include flexible learning approaches and provision of scholarships (Giannini, Jenkins \& Saavedra, 2020).

Girls and young mothers must be encouraged, not barred from returning to school. Social media platforms and virtual safe spaces can be created for girls with access to mobile phones. To reach the most marginalised girls, safe, in-person encounters may be required (Naylor \& Gorgen, 2020). Campaign messaging should be tailored to the local context and counter harmful gender norms (Jenkins \& Winthrop, 2020). For example, the shutdown of school systems during the Ebola epidemic led to a significant increase in teenage pregnancies and gender-based violence. After the epidemic, when schools reopened, pregnant girls in Sierra Leone were banned from school (Watt, 2020). In recent months, Sierra Leone has issued a policy that will allow pregnant girls to return to school with other students (lenkins \& Winthrop, 2020).

The campaign should additionally target individuals who were out of school prior to the COVID-19 pandemic. Rejoining a class may be easier for these students, given that all students will be re-acclimating to the classroom (UNESCO, UNICEF, World Bank, \& WFP, 2020).

\section{Box 5. Recommendation for Bangladesh: Ensure marginalised learners are supported.}

Initiatives should target out of school children (OOSC), girls, children with special educational needs and disabilities (SEND), and children from ethnic minorities. Any campaign should leverage COVID-19-related activities being undertaken in other sectors in Bangladesh. For example, educational materials can be packaged with existing food and health supplies for widespread distribution.

\subsection{Equip teachers with support and curriculum materials}

Providing teachers with guidance on COVID-19 can be an important factor in combating outbreaks. Teachers can effectively share information with students and their families through community events on symptoms and ways to prevent infection. In Nigeria, after Ebola was contained, at least two faculty members from every school were trained on Ebola prevention measures (Global Business Coalition for Education, 2014). The Guinea 
Ministry of Education redesigned teacher education programmes to include lessons on Ebola and related issues, benefiting over 12,000 teachers (World Bank, 2015).

Teachers and local education staff must be engaged through guidance and materials on effectively addressing learning gaps (UNESCO, UNICEF, World Bank, \& WFP, 2020). In 2015, Liberia provided 15,000 teachers with curriculum refresher sessions following the Ebola outbreak (World Bank, 2015). ICT can further supplement a framework of teacher practices by enabling virtual coaching and setting up peer networks through platforms such as WhatsApp, Skype, and Telegram (Haßler, Allier-Gagneur, McBurnie, \& Damani, 2020).

Box 6. Recommendation for Bangladesh: Share Open Educational Resources (OER) with teachers for professional development and lesson planning.

A range of OER materials for teacher support are available. For example, OER4Schools serves as a professional learning resource for teachers and is freely available. The resource covers interactive teaching principles through YouTube videos and online materials that can be downloaded as pdfs for offline usage (University of Cambridge, 2015).

Open textbooks and teacher guides are also available. Siyavula, an organization based in South Africa, offers free downloads of Mathematics and Science textbooks and lesson plans for use by students and teachers (Siyavula, 2020). In India and Sri Lanka, textbooks can be downloaded directly from the Ministry of Education websites (Educational Publications Department, 2015; National Council of Educational Research and Training, 2020).

\subsection{COVID-19 accelerated funding and back-to-school strategies}

GPE recently awarded USD 60 million in grants in response to COVID-19 to support education in Ghana, Malawi, Mozambique, Rwanda and Zambia. In addition to developing remote learning programming, grants will cover back-to-school strategies (see Figure 5 and Annex) (Global Partnership for Education, 2020b).

Figure 5. Mapping key elements of back to school strategies to GPE funding proposals (Global Partnership for Education, 2020b). Sources: COVID-19 Accelerated Funding Applications from Ghana Malawi Mozambique, Rwanda, and Zambia.

\begin{tabular}{|l|c|c|c|c|c|}
\hline & Ghana & Malawi & Mozambique & Rwanda & Zambia \\
\hline (1) Alignment & & $X$ & & $X$ & $X$ \\
\hline (2) Communications & $X$ & $X$ & & $X$ & $X$ \\
\hline (3) Sanitation & $X$ & $X$ & $X$ & $X$ & $X$ \\
\hline $\begin{array}{l}\text { (4) Student and } \\
\text { parent support }\end{array}$ & $X$ & $X$ & $X$ & $X$ & $X$ \\
\hline
\end{tabular}


HDR18. Bangladesh Back to School Campaign

\begin{tabular}{|l|c|c|c|c|c|}
\hline $\begin{array}{l}\text { (5) Marginalised } \\
\text { learners }\end{array}$ & $X$ & $X$ & $X$ & $X$ & $X$ \\
\hline (6) Teacher support & & & $X$ & & $X$ \\
\hline
\end{tabular}




\section{References}

Berry, C. (2015). Ebola, Education And Innovation In Sierra Leone. DFID. https://dfid.blog.gov.uk/2015/09/11/ebola-education-and-innovation-in-sierra-leo nel

Bhattacherjee, A. (2018). Behind Bangladesh's Protests: Rising Frustration. The Diplomat. https://thediplomat.com/2018/08/behind-bangladeshs-protests-rising-frustration 1

Briggs, B. (2018). Safe Schools: getting children back into education after disaster strikes. Theirworld.

https://theirworld.org/news/safe-schools-getting-children-back-into-education-af ter-natural-disaster

Daems, T. \& Willemot, Y. (2018). Getting back to normal after Ebola strikes. UNICEF. https://www.unicef.org/stories/getting-back-normal-after-ebola-strikes

Davis, E. \& Berry, C. (2020). Mitigating COVID-19 impacts and getting education systems up and running again: Lessons from Sierra Leone. Global Partnership for Education. https://www.globalpartnership.org/blog/mitigating-covid-19-impacts-and-gettingeducation-systems-and-running-again-lessons-sierra

Directorate of Primary Education. (2019). Bangladesh Primary Education Annual Sector Performance Report 2019.

Educational Publications Department. (2015). Text Books Download. www.edupub.gov.Ik/BooksDownload.php

EduHub Bangladesh. (2020). घরে বসেই শিফ্কা. https://www.eduhub.gov.bd

Giannini, S., Jenkins, R., \& Saavedra, J. (2020). Reopening schools: When, where and how? World Bank Blogs.

https://blogs.worldbank.org/education/reopening-schools-when-where-and-how

Global Business Coalition for Education. (2014). Ebola Emergency: Restoring Education, Creating Safe Schools and Preventing a Long-term Crisis.

https://gbc-education.org/wp-content/uploads/2014/12/EbolaandEducationRepo rt122014.pdf

Global Partnership for Education. (2020). Ghana COVID-19 Accelerated Funding Application Form.

https://www.globalpartnership.org/sites/default/files/document/file/2020-04-CO VID-accelerated-funding-Ghana\%20Updated\%20Proposal\%20May\%205\%202020 \%20final.pdf

Global Partnership for Education. (2020). Global Partnership for Education provides $\$ 68$ million in grants for education response to COVID-19 (coronavirus).

https://www.globalpartnership.org/news/global-partnership-education-provides68-million-grants-education-response-covid-19

Global Partnership for Education. (2020). Grant request to finance Rwanda COVID-19 
education response from COVID-19 accelerated funding window under the GPE fund. https://www.globalpartnership.org/sites/default/files/document/file/2020-05-11Rwanda-COVID-19-Application 0.pdf

Global Partnership for Education. (2020). Programa de Educação em Emergência 2020-2021 financiado pela Parceria Global da Educação.

https://www.globalpartnership.org/sites/default/files/document/file/2020-05-18COVID-19\%20AFF\%20Request\%20Mozambique.pdf

Global Partnership for Education. (2020). Proposal for GPE Accelerated Funding for COVID-19 Response (Malawi).

https://www.globalpartnership.org/sites/default/files/document/file/2020-05-CO VID-19\%20AFF\%20Request\%20Malawi 0.pdf

Global Partnership for Education. (2020). Zambia COVID-19 Accelerated Funding Application Form.

https://www.globalpartnership.org/sites/default/files/document/file/2020-04-CO VID-accelerated-funding-Zambia-Proposal-April-29-final\%20.pdf

Haßler, B., Allier-Gagneur, Z., McBurnie, C. \& Damani, K. (2020). Characteristics of effective teacher education in low- and middle-income countries: a detailed summary of evidence on teacher education. (EdTech Hub Helpdesk Response No. 10B).

Interagency Collaboration on Ebola. (2015). Situation Report No. 11. https://www.humanitarianresponse.info/en/node/114079

Inveneo. (2014). Key ICT Features in UNICEF'S Response to Fighting Ebola.

http://www.inveneo.org/2014/11/key-ict-features-in-unicefs-response-to-fightingebolal

International Institute for Educational Planning. (2020). Reopening schools: How to get education back on track after COVID-19. UNESCO.

www.iiep.unesco.org/en/reopening-schools-how-get-education-back-track-after-c ovid-19-13424

Jenkins, R. \& Winthrop, R. (2020). 5 actions to help bring the most marginalized girls back to school after COVID-19. The Brookings Institution. https://www.brookings.edu/blog/education-plus-development/2020/05/15/5-acti ons-to-help-bring-the-most-marginalized-girls-back-to-school-after-covid-19/

Linden, T. (2001). Double-Shift Secondary Schools: Possibilities and Issues. https://documents.worldbank.org/curated/en/819151468740107174/pdf/multiop age.pdf

Ministry of Primary and Mass Education. (2020). COVID-19 Response and Recovery Plan. https://mopme.gov.bd/site/notices/9fca7342-6a60-49a5-9eb8-500d15c51904/CO VID-19-Response-and-Recovery-Plan-of-Ministry-of-Primary-and-Mass-Ed

National Council of Educational Research and Training. (2020). Textbook. www.ncert.nic.in/NCERTS/textbook/textbook.htm

Naylor, R. \& Gorgen, K. (2020). Overview of emerging country-level response to 
providing educational continuity under COVID-19.

https://edtechhub.org/wp-content/uploads/2020/05/marginalised-girls.pdf

Siyavula. (2020). Our Work. https://www.siyavulaeducation.com/work-oer.html

Theirworld. (2018). Safe Schools: The Hidden Crisis.

http://s3.amazonaws.com/theirworld-site-resources/Reports/Theirworld-ReportSafe-Schools-December-2018.pdf

Tounsi, S. (2018). Back to school - but classes are empty because of Ebola fears in DRC. Theirworld.

https://theirworld.org/news/ebola-fears-keep-children-off-school-in-drc

UNESCO, UNICEF, World Bank, \& WFP. (2020). Framework for reopening schools.

https://unesdoc.unesco.org/ark:/48223/pf0000373348/PDF/373348eng.pdf.multi

UNICEF. (2013). UNICEF Back-to-School Guide: Evidence-Based Strategies to Resume Education in Emergencies and Post-Crisis Transition.

https://reliefweb.int/sites/reliefweb.int/files/resources/UNICEF Back To School Guide 2013.pdf

UNICEF. (2017). Ministry of Education joins UN in launching Back to School campaign. https://www.unicef.org/lebanon/press-releases/ministry-education-joins-un-laun ching-back-school-campaign

University of Cambridge. (2015). The OER4Schools Professional Learning Resource. https://oer.educ.cam.ac.uk/wiki/OER4Schools

Uttom, S. \& Rozario, R. (2020). Covid-19 disrupts education in rural Bangladesh. UCA News. https://www.ucanews.com/news/covid-19-disrupts-education-in-rural-banglades $\underline{\mathrm{h} / 87976}$

Watt, E. (2020). From Ebola to coronavirus: education must not be forgotten in a health crisis. Theirworld.

https://theirworld.org/news/ebola-to-coronavirus-education-vital-in-health-crisis

World Bank. (2015). Back to School After the Ebola Outbreak.

https://www.worldbank.org/en/news/feature/2015/05/01/back-to-school-after-eb ola-outbreak

WFP. (2020). WFP and Government of Bangladesh deliver high-energy biscuits to school children affected by COVID-19 school closures. ReliefWeb. https://reliefweb.int/report/bangladesh/wfp-and-government-bangladesh-deliver -high-energy-biscuits-school-children 


\section{Annex: Back to school activities outlined in GPE funding proposals}

Sources: COVID-19 Accelerated Funding Applications from Ghana, Malawi, Mozambique, Rwanda, and Zambia.

\begin{tabular}{|c|c|}
\hline Country & Proposal activities \\
\hline Ghana & $\begin{array}{l}\text { - Develop a radio and TV-based campaign on health, safety, } \\
\text { prevention of gender-based violence and early pregnancy, and } \\
\text { importance of returning to school } \\
\text { - Launch campaign across } 16 \text { regions within } 60 \text { days of schools } \\
\text { reopening; campaign will last for over } 2 \text { weeks } \\
\text { - Target inclusion of children with disabilities, and girls } \\
\text { - Develop communications that are child-friendly and accessible } \\
\text { to people in rural areas, with limited literacy, etc. } \\
\text { - Sanitise schools, especially those used for emergency } \\
\text { response and treatment of the ill }\end{array}$ \\
\hline Malawi & $\begin{array}{l}\text { - Partner with community groups and mass media to } \\
\text { encourage families to send children back to school } \\
\text { - Provide catch up classes to counter learning loss } \\
\text { - Ensure that hand-washing facilities are available and children } \\
\text { are instructed to wash their hands regularly at each school } \\
\text { - Provide recreational materials to students } \\
\text { - Establish protection services and referrals for a safe school } \\
\text { environment }\end{array}$ \\
\hline Mozambique & $\begin{array}{l}\text { - Restock textbooks in priority schools } \\
\text { - } \text { Offer remedial classes and accelerated learning for students } \\
\text { who have fallen behind in their coursework } \\
\text { - Use a Building-Back-Better (BBB) approach to reconstruct } \\
\text { classrooms that were affected by } 2019 \text { tropical storms with } \\
\text { sanitary facilities and inclusive measures } \\
\text { - Launch school feeding and student funds programmes } \\
\text { - Provide hygiene kits for girls } \\
\text { - Strengthen teacher participation in psychosocial support for } \\
\text { themselves and their students }\end{array}$ \\
\hline Rwanda & $\begin{array}{l}\text { - Launch campaign to raise awareness in communities about } \\
\text { disease prevention } \\
\text { - Target districts with }>45 \% \text { of the population below the } \\
\text { national poverty line } \\
\text { - Use information from the school data management system } \\
\text { (SDMS) to provide all public schools with a water tank, and } \\
\text { grants for soap and hand-washing equipment } \\
\text { - Offer supplemental grants for school feeding and student } \\
\text { learning materials to schools ranked as poorest in the Fifth } \\
\text { Integrated Household Living Survey }\end{array}$ \\
\hline
\end{tabular}


Zambia

- Partner across sectors to conduct back-to-school campaign

- Provide psychosocial support to families, teachers, and students

- Orient learners and students on infection prevention practices

- Provide select schools with water and solar power

- Distribute teaching and learning materials

- Coordinate remedial lessons to bring children up to minimum grade level 